\title{
Impact of universal two-dose vaccination on varicella epidemiology in Navarre, Spain, 2006 to 2012
}

M García Cenoz (mgcenoz@navarra.es) ${ }^{1,2}$, J Castilla ${ }^{1,2}$, J Chamorro3, I Martínez-Baz ${ }^{1,2}$, V Martínez-Artola ${ }^{3}$, F Irisarri ${ }^{1,2}$, M Arriazu ${ }^{1,2}$, C Ezpeleta ${ }^{3}$, A Barricarte ${ }^{1,2}$

1. Instituto de Salud Pública de Navarra, Pamplona, Spain

2. CIBER Epidemiología y Salud Pública (CIBERESP), Pamplona, Spain

3. Complejo Hospitalario Navarra, Pamplona, Spain

García Cenoz M, Castilla J, Chamorro J, Martínez-Baz I, Martínez-Artola V, Irisarri F, Arriazu M, Ezpeleta C, Barricarte A. Impact of universal two-dose vaccination on varicella epidemiology in Navarre, Spain, 2006 to 2012. Euro Surveill. 2013;18(32):pii=20552. Available online: http://www.eurosurveillance.org/ViewArticle. aspx?Articleld $=20552$

Article submitted on 17 September 2012 / published on 08 August 2013

In 2007 in Navarre, Spain, universal varicella vaccination with two doses of Varivax was introduced in the childhood immunisation schedule for children aged 15 months and three years. This study describes changes in the epidemiology of varicella in the period 2006 to 2012 and evaluates vaccination effectiveness using epidemiological surveillance data. The incidence of varicella in children aged 0 to 14 years decreased by $98.1 \%$, from 50.1 cases per 1,000 inhabitants in 2006 , to 1.0 per 1,000 in 2012 . Children aged one to eight years were the vaccinated cohorts, and their incidence of varicella decreased by $98.5 \%$ ( $p<0.0001)$. In unvaccinated age groups, important reductions were also achieved between 2006 and 2012: 90.5\% (p<0.0001) in infants under one year of age, and $89.4 \%$ (p<0.0001) in children aged nine years. In the period 2006 to 2012, the hospital admissions rate for varicella or its complications decreased by $89.0 \%$, and in 2012 , there was only one admission of a newborn with neonatal varicella. Vaccine effectiveness for at least one dose was $96.8 \%$ ( $95 \%$ confidence interval: $96.3-97.2 \%$ ). Universal vaccination with two doses has reduced varicella circulation to minimum levels within five years and has proved highly effective.

\section{Introduction}

In the absence of vaccination, varicella-zoster virus (VZV) circulates widely and infects most people during childhood [1]. Varicella typically occurs during the school year, with outbreaks affecting classmates and family members [2-5]. In 1995 the first varicella vaccine, with one dose, was introduced in the childhood vaccination schedule in the United States (US). Subsequent years saw a reduction, not only of cases of varicella, but also of hospitalisations due to its complications [6-8]. In other countries like Australia [9,10], Germany [11] and Italy (Region of Veneto) [12], universal childhood vaccination against varicella has had similar effects.

Despite high one-dose vaccination coverage and the success of the vaccination programme in the US, the occurrence of continued outbreaks in highly vaccinated populations and an increasing number of vaccine failures $[8,13]$ led the Advisory Committee on Immunization Practices (ACIP) in 2006 to recommend a second dose of the vaccine [4]. The two-dose scheme is expected to have a rapid and pronounced impact on the control of varicella circulation [14].

Thanks to herd immunity, varicella vaccine protects not only those who are vaccinated, but also the unvaccinated, since the probability that susceptible individuals will come into contact with the VZV diminishes $[15,16]$. This indirect effect could also contribute to the impact of a universal varicella vaccination programme. Most studies have evaluated the impact of varicella vaccination programmes which started with a singledose scheme or which introduced the second dose after a period of using a one-dose programme. It would be interesting to have evidence on the potential impact of the introduction of varicella vaccination in childhood with a two-dose scheme.

Navarre is a Spanish region with 644.566 inhabitants in 2012, of whom 100.282 were under 15 years-old. The Navarre Health Service provides healthcare, free at point of service, to $97 \%$ of the population; it comprises one tertiary hospital in the main city, two small local hospitals, all of them with paediatric wards and emergency rooms, and 54 primary healthcare centres. The clinical reports have been computerised since 2000, and include those from both primary care and hospital admissions. All vaccine doses administered are registered at the vaccination points.

In 2004, Navarre began varicella vaccination for all susceptible individuals (individuals with no history of varicella and who had not been previously vaccinated) at age 14 years for cohorts born since 1990. In 2006 , the age of vaccination of susceptible children was lowered to 10 years for all those born since 1996. A school catch-up vaccination was performed for susceptible persons born between 1992 and 1995. In 2007 , 
universal vaccination with two doses was introduced for all children born since 2006. The schedule calls for the first dose of vaccine at the age of 15 months and a second dose at the age of three years. In order to obtain a rapid decrease in varicella cases, all children born in 2004 and 2005 were offered vaccination with one dose at the age of three years. In addition, vaccination of susceptible individuals continued for all children who had not received universal vaccination (those born between 1996 and 2003). In 2011, a second dose of vaccine was offered to all cohorts who had previously received only one dose.

Varicella and measles-mumps-rubella vaccinations in Navarre are administered at the same time, but in separate vaccines. Varilrix was used for vaccination of susceptible adolescents until the end of 2006, and Varivax was used for all vaccinations after that. In the period from 2009 to 2012, vaccination coverage was around $95 \%$ for the first and second doses of measles-mumpsrubella vaccine and the first varicella vaccine dose, and over $89 \%$ for the second varicella vaccine dose (data not shown).

The aim of this study is to describe the epidemiology of varicella in Navarre, Spain, since the introduction of universal vaccination with a two-dose scheme, in terms of its impact on both vaccinated cohorts (direct effect) and unvaccinated cohorts (indirect effect), and to assess the vaccine effectiveness.

\section{Methods}

\section{Study design and information sources}

Varicella is a notifiable disease in Navarre [17]. From the electronic clinical reports of primary healthcare, automatic notification of all diagnoses of varicella (ICPC-2 code A72) is generated according to the International
Classification of Primary Care, Second Edition (ICPC-2) [18], including the date of consultation, date of birth, sex and vaccination history.

Varicella surveillance in hospitals is conducted by trained nurses, who review clinical and laboratory reports daily to search for cases among admitted patients. At the end of each year this information is validated with hospital discharge diagnoses. In the present study, we considered all admissions with a principal diagnosis of varicella (ICD-9 code 052.9) or complication of varicella (ICD-9 codes 052.0, 052.1, 052.7, 052.8) according to the International Classification of Diseases, Ninth Revision, Clinical Modification (ICD9-CM) [19]. A unique patient identification number was used to detect and exclude duplicate cases. The number of vaccine doses received, the date and the brand name were taken from the regional vaccination registry.

In the cohorts of vaccinated children, three possible explanations for cases of varicella were considered according to the temporal criteria already described [20]: Cases with onset in the first 14 days after the first vaccine dose were considered as not related to the vaccine; those occurring between 15 and 42 days after receipt of a vaccine dose were attributed to the vaccine virus, and all cases occurring more than 42 days after administration of a dose of varicella vaccine were considered vaccine failures or breakthrough varicella.

\section{Statistical analysis}

To calculate incidence rates, we used as the denominator the population of Navarre at the beginning of each year, according to the National Statistics Institute [21] of Spain. To assess the impact of vaccination, we compared the incidence in $\mathbf{2 0 1 2}$ with the incidence in 2006, the year before universal vaccination was initiated. We

\section{FIGURE 1}

Notified varicella cases, by four-week period, Navarre, 2006-2012 (n=10,477)

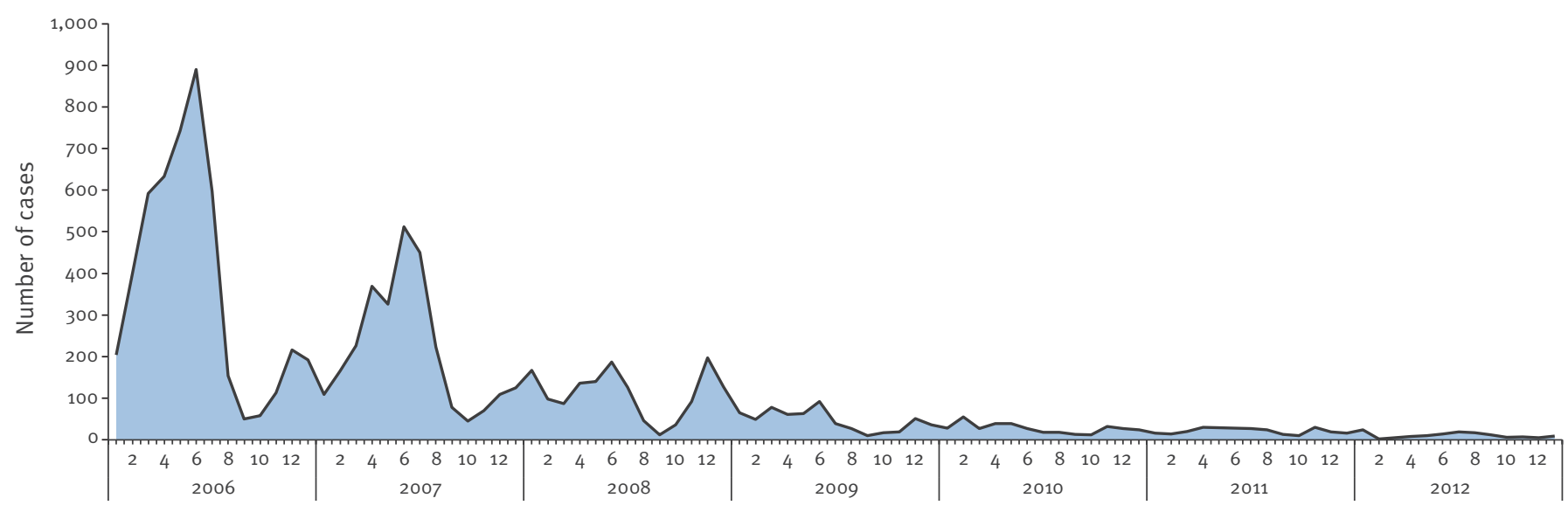

Year and four - week period 


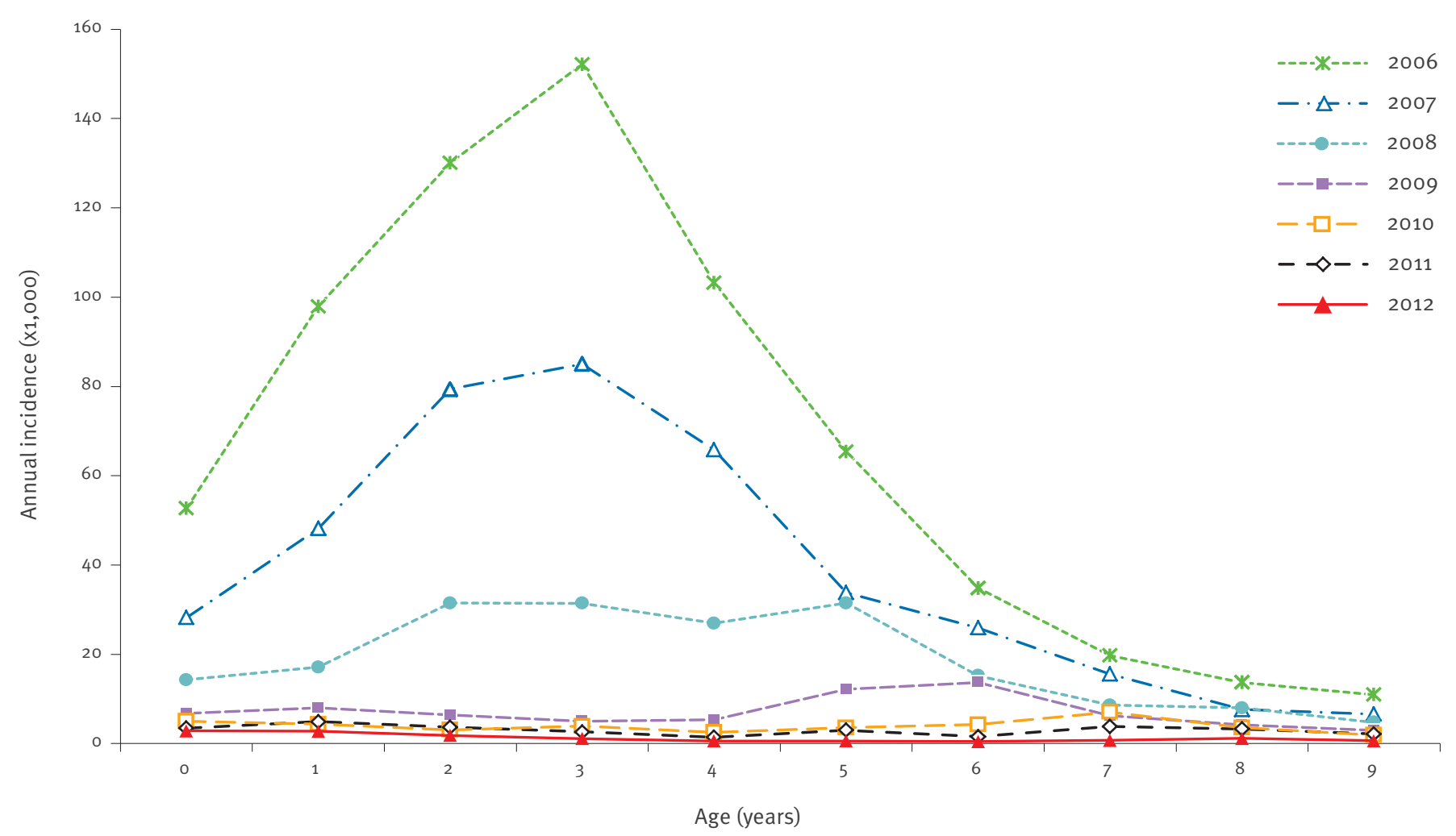

evaluated the direct effect of vaccination in age groups in which universal vaccination was offered, and the indirect effect (herd immunity) in unvaccinated age groups. The chi-square test and Fisher's exact test were used for the statistical analysis.

Varicella vaccine effectiveness for at least one dose was calculated using the screening method proposed by Farrington [22], based on a comparison of the proportion of vaccinated persons among the cases and the population. Vaccine effectiveness (VE) is then given by the expression:

$$
\mathrm{VE}=1-\left[\frac{\mathrm{PCV}}{(1-\mathrm{PCV})} \mathrm{x} \frac{(1-\mathrm{PPV})}{\mathrm{PPV}}\right]
$$

where PCV is the proportion of cases vaccinated and PPV is the proportion of the population vaccinated. We estimated vaccine effectiveness in the birth cohorts born between 2004 and 2010 that had received the vaccine between 2007 and 2012.

\section{Results}

Figure 1 shows the time trend of varicella incidence in Navarre in 2006 to 2012. Of note is the marked seasonality in the first years, with peaks in late spring, and a rapid reduction in incidence during the study period.

\section{Incidence of varicella}

From 2006 to 2012, 10,477 cases of varicella were diagnosed in primary healthcare, $50.7 \%$ in males, $62.5 \%$ in children under five years-old, and $87.6 \%$ in those younger than 15 years. The incidence of varicella decreased progressively, from 8.04 cases per 1,000 inhabitants in 2006 to 0.21 per 1,000 in 2012 , a reduction of $97.3 \%$ (p<o.0001). The incidence of varicella in children aged o to 14 years decreased from 50.1 cases per 1,000 inhabitants in 2006 to 1.0 cases per 1,000 in 2012 , which represented a $98.1 \%$ reduction.

While $82.9 \%$ of cases occurred in children under age 15 in 2006 , this percentage decreased to $70.3 \%$ in 2012. Furthermore, the peak incidence of varicella have moved, from the three year-olds in 2006 to a situation with two small peaks in 2012, corresponding to children under 15 months-old and children aged nine years, as these children have not yet been vaccinated (Figure 2).

\section{Impact of varicella vaccination}

In children aged one to eight years, the cohorts vaccinated in the universal vaccination programme, the incidence of varicella decreased by $98.5 \%$ (p<0.0001). Important reductions were also observed in cohorts vaccinated at age 10 to 21 years. The incidence declined by $93.8 \%$ ( $p<0.0001$ ) among the 10 to 16 year-olds and 
Annual incidence of varicella per 1,000 inhabitants among age groups included in universal vaccination (1-8 years) and vaccination of susceptibles (10-21 years), Navarre, 2006-2012

\begin{tabular}{|c|c|c|c|c|c|c|c|c|}
\hline Age groups & 2006 & 2007 & 2008 & 2009 & 2010 & 2011 & 2012 & $\begin{array}{l}\% \text { reduction } \\
2006-2012\end{array}$ \\
\hline \multicolumn{9}{|c|}{ Universal vaccination } \\
\hline 1 year & 70.1 & 32.8 & 19.2 & 8.5 & 5.3 & 5.1 & 2.9 & $95 . \%^{c}$ \\
\hline 2 years & 117.9 & 67.3 & 11.3 & 7.3 & 3.8 & 3.6 & 2.7 & $97.7 \%^{\mathrm{c}}$ \\
\hline 3 years & 133.0 & 78.0 & 46.7 & 5.2 & 3.6 & 3.5 & 1.4 & $99.0 \%^{c}$ \\
\hline 4 years & 142.8 & 86.3 & 15.3 & 5.4 & 3.3 & 1.3 & 0.7 & $99.5 \%^{\mathrm{c}}$ \\
\hline 5 years & 94.9 & $49 \cdot 3$ & 43.0 & 4.5 & 2.8 & 2.2 & 0.3 & $99.7 \%^{\mathrm{c}}$ \\
\hline 6 years & 51.7 & 30.0 & 21.4 & 21.7 & 3.5 & 2.5 & 0.7 & $98.6 \%^{c}$ \\
\hline 7 years & 28.3 & 19.7 & 9.5 & 7.4 & 6.3 & 1.6 & 0.3 & $99.0 \%^{c}$ \\
\hline 8 years & 14.4 & 12.5 & 9.8 & 5.2 & 5.9 & 5.0 & 0.7 & $94.9 \%^{\mathrm{c}}$ \\
\hline Total $1-8$ years & 92.1 & 52.6 & 23.9 & 8.5 & 4.1 & 2.8 & 1.2 & $98.5 \%^{\mathrm{c}}$ \\
\hline \multicolumn{9}{|c|}{ Vaccination of susceptibles } \\
\hline $10-16$ years $^{\mathrm{a}}$ & $7 \cdot 3$ & 2.0 & 1.6 & 1.5 & 0.6 & 0.4 & 7.3 & $95.6 \%^{\mathrm{c}}$ \\
\hline 17-21 years ${ }^{b}$ & 2.7 & 1.4 & 0.6 & 0.6 & 0.4 & 0.2 & 0.3 & $90.1 \%^{c}$ \\
\hline
\end{tabular}

a Vaccinated at 10 years of age.

b Vaccinated at 11, 12, 13 or 14 years of age.

p value $<0.001$

by $90.1 \%$ ( $p<0.0001)$ in persons aged 17 to 21 years (Table 1).

Also in unvaccinated age groups, important reductions were achieved between 2006 and 2012: 90.5\% ( $p<0.0001$ ) in infant under the age of one year, and $89.4 \%$ in nine-year old children. In people older than 21 years, the overall reduction was $92.4 \%$ ( $p<0.0001)$ (Table 2).

Before the introduction of universal vaccination, most cases $(77.7 \%)$ occurred in winter and spring, with a peak in weeks 21 to 24 (second half of May to first half of June). A slight change in the seasonality of varicella was observed, in that in 2012 , only $52.2 \%$ of cases occurred in that period. Moreover, due to an overall reduction in varicella incidence, cases in 2012 were distributed more homogeneously throughout the year, especially from autumn to spring.

Varicella in vaccinated individuals and breakthrough varicella Between January 2007 and March 2013, 42,860 children born between 2004 and 2011 were vaccinated against varicella: 14,617 received only one dose and 28,243 had two doses. In these birth cohorts, 2,448 cases of varicella were diagnosed until December 2012, 260 of which (10.6\%) occurred in vaccinated children. Considering the time interval between the last dose and symptom onset, 22 cases were considered to be vaccine cases (0.9\%) and 238

\section{TABLE 2}

Annual incidence of varicella per 1,000 inhabitants in unvaccinated age groups (indirect effect), Navarre, Spain, 2006-2012

\begin{tabular}{|c|c|c|c|c|c|c|c|c|c|}
\hline Age groups & 2006 & 2007 & 2008 & 2009 & 2010 & 2011 & 2012 & $\begin{array}{c}\% \\
\text { reduction } \\
2006-2012\end{array}$ & $p$ \\
\hline < 1 year & 12.5 & 8.7 & 5.5 & 1.9 & 1.5 & 1.3 & 1.2 & $90.5 \%$ & $<0.0001$ \\
\hline 9 years & 11.7 & 6.3 & 5.9 & 3.0 & 2.4 & 2.9 & 1.2 & $89.4 \%$ & $<0.0001$ \\
\hline $22-24$ years & 1.6 & 1.2 & 0.6 & 0.4 & 0.3 & 0.1 & 0.1 & $96.8 \%$ & $<0.0001$ \\
\hline $25-44$ years & 1.6 & 0.9 & 0.6 & 0.3 & 0.2 & 0.2 & 0.05 & $92.4 \%$ & $<0.0001$ \\
\hline $45-64$ years & 0.2 & 0.2 & 0.1 & 0.08 & 0.06 & 0.07 & 0.04 & $84.6 \%$ & 0.0015 \\
\hline$\geq 65$ years & 0.1 & 0.07 & 0.04 & 0.03 & 0.02 & 0.02 & 0.01 & $91.7 \%$ & 0.0526 \\
\hline Total $\geq 22$ years & 0.8 & 0.5 & 0.3 & 0.2 & 0.1 & 0.1 & 0.06 & $92.4 \%$ & $<0.0001$ \\
\hline
\end{tabular}


Hospital admissions with diagnosis of varicella (ICD-9-CM code 052.9) and varicella with complication (ICD-9-CM codes 052.0, 052.1, 052.7 and 052.8), Navarre, Spain, 2006-2012 ( $\mathrm{n}=71)$

\begin{tabular}{|c|c|c|c|c|c|c|c|c|}
\hline & 2006 & 2007 & 2008 & 2009 & 2010 & 2011 & 2012 & $\begin{array}{l}\% \text { reduction } \\
2006-2012\end{array}$ \\
\hline \multicolumn{9}{|l|}{ Total population } \\
\hline Hospital admissions & 25 & 22 & 11 & 7 & 1 & 2 & 3 & $88 \%$ \\
\hline Average stay (days) & 5.9 & 5.0 & 3.4 & 5.0 & 6.0 & 1.5 & $4 \cdot 3$ & NA \\
\hline Admissions per 100,000 & 4.2 & 3.6 & 1.8 & 1.1 & 0.3 & 0.3 & 0.5 & $89 \%$ \\
\hline Number of complicated varicella & 10 & 10 & 2 & 3 & 0 & 0 & 0 & NA \\
\hline \multicolumn{9}{|l|}{ Children $<15$ years } \\
\hline Hospital admissions & 18 & 14 & 9 & 2 & 0 & 0 & 1 & $94 \%$ \\
\hline Average stay (days) & $5 \cdot 9$ & 4.6 & 3.2 & 4.0 & NA & NA & 3,0 & NA \\
\hline Admissions per 100,000 & 20.9 & $15 \cdot 9$ & 9.9 & 2.1 & 0 & 0 & 1,0 & $95 \%^{a}$ \\
\hline Number of complicated varicella & 5 & 6 & 1 & 1 & 0 & 0 & 1 & NA \\
\hline
\end{tabular}

NA: not applicable.

a $\mathrm{p}$ value $=0.0001$

as vaccine failures or breakthrough varicella (9.7\%). One medical consultation for varicella attributable to the vaccine virus was produced for every 3,231 doses administered: one consultation for every 2,381 first doses, and one for every 7,060 second doses. About $82 \%$ of vaccine-attributable cases of varicella occurred after administration of the first dose.

Among the 42,860 vaccinated children, 238 cases of breakthrough varicella were diagnosed (0.56\%). About $85 \%$ of vaccine failures $(n=202)$ occurred after administration of the first dose, corresponding to $1.38 \%$ of those vaccinated with one dose), while 36 vaccine failures occurred after the second dose (0.13\% of those vaccinated with two doses; pro.0001). One medical consultation for breakthrough varicella was produced for every 299 doses administered: one consultation for every 212 first doses, and one for every 785 second doses.

Hospitalisations due to varicella

The incidence rate of hospitalisations for varicella declined by $89 \%$, from 4.2 per 100,000 inhabitants in 2006 to 0.5 per 100,000 in 2012 (p<0.0001). In children under 15 years the rate declined by $95 \%$, from 20.9 to 1.0 per 100,000 ( $p<0.0001$ ), with only one hospitalisation of a newborn with neonatal varicella (Table 3 ).

\section{Effectiveness of varicella vaccine}

Between 2007 and 2012, 36,971 of the 47,908 children born between 2004 and 2010 had received at least one dose of varicella vaccine $(77.2 \%)$. In the same period, 2,422 cases of varicella were diagnosed in children

\section{TABLE 4}

Estimated vaccine effectiveness of any dose of varicella vaccine in vaccinated cohorts (children born between 2004 and 2010), Navarre, 2007-2012

\begin{tabular}{|c|c|c|c|c|c|c|c|c|}
\hline \multirow{3}{*}{$\begin{array}{l}\text { Birth year } \\
2004 \\
\end{array}$} & \multicolumn{3}{|c|}{ Population } & \multicolumn{3}{|c|}{ Varicella cases } & \multirow{2}{*}{\multicolumn{2}{|c|}{$\begin{array}{l}\text { Vaccine effectiveness } \\
\text { (95\% confidence interval) }\end{array}$}} \\
\hline & \multirow{2}{*}{$\begin{array}{c}n \\
6,723 \\
\end{array}$} & \multicolumn{2}{|c|}{$\begin{array}{c}\text { Vaccinated } \\
\text { n (\%) }\end{array}$} & \multirow{2}{*}{$\begin{array}{c}n \\
678 \\
\end{array}$} & \multicolumn{2}{|c|}{$\begin{array}{c}\text { Vaccinated } \\
\text { n (\%) }\end{array}$} & & \\
\hline & & 2,357 & （35） & & 19 & (3) & 94.7 & $(91.6-96.6)$ \\
\hline 2005 & 6,612 & 3,104 & $(47)$ & 819 & 23 & (3) & 96.7 & $(95.1-97.8)$ \\
\hline 2006 & 6,869 & 6,004 & $(87)$ & 355 & 86 & $(24)$ & 95.4 & $(94.2-96.3)$ \\
\hline 2007 & 6,881 & 6,207 & (90) & 271 & 47 & (17) & 97.7 & $(96.9-98.3)$ \\
\hline 2008 & 7,135 & 6,587 & (92) & 147 & 29 & $(20)$ & 98.0 & $(97.0-98.6)$ \\
\hline 2009 & 6,917 & 6,434 & (93) & 87 & 24 & $(28)$ & 97.1 & $(95.5-98.2)$ \\
\hline 2010 & 6,771 & 6,278 & (93) & 65 & 10 & $(15)$ & 98.6 & $(97.2-99.3)$ \\
\hline $2004-2010$ & 47,908 & 36,971 & $(77)$ & 2,422 & 238 & (10) & 96.8 & $(96.3-97.2)$ \\
\hline
\end{tabular}


born between 2004 and 2010, and 238 of these cases had previously been vaccinated (9.8\%). Accordingly, the effectiveness of at least one dose of varicella vaccine was $96.8 \%$ (95\% confidence interval: $96.3-$ $97.2 \%)$. Table 4 shows the effectiveness for each birth cohort, which ranged from $94.7 \%$ to $98.6 \%$.

\section{Discussion}

Universal varicella vaccination with a two-dose scheme has greatly reduced the impact of this disease in the whole population of Navarre. The reduction was particularly great in the vaccinated cohorts of children aged one to eight years, with a $98.5 \%$ decline in incidence within a period of only five years, higher than that reported in other places where universal vaccination has been introduced, such as the US and the Veneto region in Italy $[6,12,23-25]$. An important reduction in varicella incidence was also noted in persons aged 10 to 21 years, in cohorts included in the strategy of vaccination of susceptibles. Such marked declines may be explained by the introduction of universal vaccination with two doses from the beginning, and the high coverage achieved since the first year.

Varicella incidence also decreased considerably in the unvaccinated cohorts, especially in infants under the age of one year (90.5\%), which can be attributed to a herd immunity effect due to reduced circulation of VZV [16]. In children aged nine years and persons over the age of 21 years, significant reductions are also noted, whereas the impact in older adults was lower given that the incidence of the disease in this group had already been low before. All these changes have led to a slight forward shift in the age pattern of this disease. The proportion of cases under 15 years-old have declined, and the peak incidence, which typically occurred at the age of three years, has shifted to the age groups not yet vaccinated, and is now much less pronounced than before.

Rates of hospitalisation for varicella declined markedly ( $88 \%)$, more pronounced and quickly than reported in other countries [7,26-28]. In children under the age of 15 years, there was only one hospitalisation in 2012, showing that vaccination has had a substantial impact in reducing severe and complicated forms of varicella.

Because it contains attenuated virus, the varicella vaccine may infrequently cause disease, generally mild, in immunocompromised individuals, although cases have also been described in immunocompetent people [29]. From an epidemiological perspective, only $0.9 \%$ of cases of varicella in vaccinated individuals in our study were attributable to the vaccine virus, given that they appeared between 14 and 42 days after vaccine administration.

We observed vaccine failures in children with one and two doses of varicella vaccine, although these cases were generally not confirmed by laboratory. Breakthrough disease can be difficult to accurately diagnose clinically and may be overreported in the absence of laboratory confirmation [14]; we defined it as a case of varicella that appears in a person who was vaccinated more than 42 days before the onset of symptoms. Other authors have reported that these cases typically exhibit a shorter duration of illness, fewer constitutional symptoms, less than 50 skin lesions, and a rash that may show an atypical appearance (maculo-papular with few or no vesicles) $[20,30]$. However, breakthrough disease also results in medical consultation and can transmit the virus to susceptible individuals, which may lead to outbreaks $[20,25]$.

The need for a second dose of vaccine has been widely assessed. Brisson et al. estimated that protection wanes by up to $3 \%$ per year, with the consequent risk of developing a breakthrough infection if exposed to VZV [31]. As has been suggested, a second dose offers additional protection and reduces the possibility of breakthrough cases [25,32-34]. Our approach to vaccine effectiveness in vaccinated cohorts showed high effectiveness (96.8\%) in a programme where most of children had received two doses. One study estimated that vaccine efficacy after a 10-year follow-up was $94.4 \%$ for one injection and $98.3 \%$ for two injections [35]. Shapiro et al. have estimated that the odds of developing varicella were $95 \%$ lower for children who received two doses than for those who received one dose of varicella vaccine in the first 2.5 years after recommendation of a routine second dose in the US vaccination programme [25].

The main limitation of the present study is its ecological design and the fact that it is based on epidemiological surveillance data. The incidence of varicella in the population usually varies over time, but the marked reductions in incidence following the introduction of the vaccine would be difficult to explain by other causes. Varicella surveillance in Navarre during the study period was based on automatic notification from electronic clinical reports, which were fully implemented throughout the healthcare network, making underreporting of cases highly unlikely and ensuring a high level of completeness of information.

Immunity to VZV might be maintained by external boosting of immunity through exposures to varicella or herpes zoster [36]. Exposure to varicella might reduce the risk of zoster [37,38] and on the other hand, its absence would lead to an increase of herpes zoster $[34,39]$. Although this possible negative effect of the two-dose universal vaccination programme has not been taken into account in this study, recent studies have not demonstrated a relationship between varicella vaccination and increase of zoster disease in the general population $[20,40,41]$. Moreover, others have reported a reduction in zoster incidence in vaccinated $[40,42]$. In this context of universal varicella vaccination, long-term studies to monitor zoster incidence will be necessary to assess whether zoster rates increase. 
This study was based on clinically diagnosed cases of varicella, which were only occasionally confirmed by laboratory. The clinical diagnosis of varicella is highly specific in the context of wide virus circulation in the population. However, in situations of very low incidence, other diseases with clinical features similar to varicella, although infrequent, may acquire appreciable weight relative to the clinical diagnoses of varicella. In order to maintain a high specificity in varicella diagnosis, it may be desirable to incorporate virological confirmation of varicella cases in populations with high vaccination coverage, especially in breakthrough cases, since, in the absence of a large number of vesicles, they might be confused with other viral syndromes.

In conclusion, five years after the inclusion of two doses of varicella vaccine in the childhood vaccination schedule of Navarre, the incidence of this disease has diminished drastically, not only in vaccinated individuals, but also in the unvaccinated, due to herd immunity. Hospital admission rates are also lower. Varicella vaccine has been shown to be highly effective. In this situation of very low incidence, it is very important to continue varicella surveillance and to assess disease trends over time; laboratory confirmation of varicella cases is also recommended.

\section{Acknowledgements}

This work has been funded by the Health Department of the Regional Government of Navarre (Project 77/09) and by the Spanish Ministry of Health and Social Services (EC11-308).
References

1. Heininger U, Seward JF. Varicella. Lancet. 2006;368(9544):1365-76. http://dx.doi.org/10.1016/S0140-6736(06)69561-5

2. Varicella vaccines. WHO position paper. Wkly Epidemiol Rec. 1998;73(32):241-8. PMid:9715106

3. Arnedo-Pena A, Puig-Barbera J, Aznar-Orenga MA, Ballester-Albiol M, Pardo-Serrano F, Bellido-Blasco JB, et al. Varicella vaccine effectiveness during an outbreak in a partially vaccinated population in Spain. Pediatr Infect Dis J. 2006;25(9):774-8.

http://dx.doi.org/10.1097/01.inf.0000232631.06763.8b PMid:16940832

4. Marin M, Guris D, Chaves SS, Schmid S, Seward JF, Advisory Committee on Immunization Practices, Centers for Disease Control and Prevention (CDC). Prevention of varicella: recommendations of the Advisory Committee on Immunization Practices (ACIP). MMWR Recomm Rep. 2007;56(RR-4):1-40. PMid:17585291

5. Ross AH. Modification of chicken pox in family contacts by administration of gamma globulin. N Engl J Med. 1962;267:36976

http://dx.doi.org/10.1056/NEJM196208232670801 PMid:14494142

6. Seward JF, Watson BM, Peterson CL, Mascola L, Pelosi JW, Zhang JX, et al. Varicella disease after introduction of varicella vaccine in the United States, 1995-2000. JAMA. 2002;287(5):606-11.

http://dx.doi.org/10.1001/jama.287.5.606 PMid:11829699

7. Grose C. Varicella vaccination of children in the United States: Assessment after the first decade 1995-2005. J Clinical Virol. 2005;33(2):89-95.

http://dx.doi.org/10.1016/j.jcv.2005.02.003

PMid:15911422

8. Seward JF, Marin M, Vazquez M. Varicella vaccine effectiveness in the US vaccination program: A review. J Infect Dis. 2008;197(Suppl 2):S82-9.

http://dx.doi.org/10.1086/522145 PMid:18419415

9. Macartney KK, Beutels P, McIntyre P, Burgess MA. Varicella vaccination in Australia. J Paediatr Child Health. 2005;41(11):544-52.

http://dx.doi.org/10.1111/j.1440-1754.2005.00717.x PMid:16398834

10. Carville KS, Riddell MA, Kelly HA. A decline in varicella but an uncertain impact on zoster following varicella vaccination in Victoria, Australia. Vaccine. 2010:28(13):2532-8. http://dx.doi.org/10.1016/j.vaccine.2010.01.036 PMid:20117265

11. Siedler A, Arndt U. Impact of the routine varicella vaccination programme on varicella epidemiology in Germany. Euro Surveill. 2010;15(13):pii=19530. Available from: http://www. eurosurveillance.org/ViewArticle.aspx?Articleld =19530

12. Pozza F, Piovesan C, Russo F, Bella A, Pezzotti P, Emberti Gialloreti L. Impact of universal vaccination on the epidemiology of varicella in Veneto, Italy. Vaccine. 2011;29(51):9480-7. http://dx.doi.org/10.1016/j.vaccine.2011.10.022 PMid:22015389

13. Vazquez M, LaRussa PS, Gershon AA, Niccolai LM, Muehlenbein CE, Steinberg SP, et al. Effectiveness over time of varicella vaccine. JAMA. 2004;291(7):851-5. http://dx.doi.org/10.1001/jama.291.7.851 PMid:14970064

14. Kattan JA, Sosa LE, Bohnwagner HD, Hadler JL. Impact of 2-dose vaccination on varicella epidemiology: Connecticut-2005-2008. J Infect Dis. 2011;203(4):509-12 http://dx.doi.org/10.1093/infdis/jiq081 PMid:21199882 PMCid:PMC3071238

15. Fox J, Elveback L, Scott W, Gatewood L, Ackerman E. Herd immunity: basic concept end relevance to public health immunization practices. Am J Epidemiol. 1971;94(3):179-89. PMid: 5093648

16. Fox J. Herd immunity and measles. Rev Infect Dis. 1983;5(3):463-6.

http://dx.doi.org/10.1093/clinids/5.3.463 PMid:6879000

17. Orden Foral $19 / 2008$, de 15 de febrero, de la Consejería de Salud, por la que se modifican las enfermedades incluidas en el Sistema de Vigilancia Epidemiológica de Navarra. [Local Order 19/2008, of 15 February, of the Ministry of Health, amending the diseases included in the Epidemiological Surveillance System of Navarra]. Boletín Oficial de Navarra. 2008:28. Spanish. Available 
from: http://sid.usal.es/leyes/discapacidad/12504/3-2-3/ orden-foral-19-2008-de-15-de-febrero-de-la-consejera-desalud-por-la-que-se-modifican-las-enfermedades-incluidas-enel-sistema-de-vigilancia-epidemiol.aspx

18. Wonca International Classification Committee (WICC). International Classification of Primary Care - 2nd Edition (ICPC-2). Bangkok: World Organization of Family Doctors (Wonca). [Accessed 10 Oct 2012]. Available from: http://www. rivm.nl/who-fic/cdromthesaurus/Pagerenglish.pdf

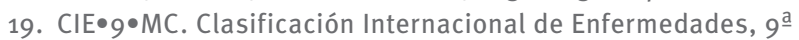
Revisión Modificación Clínica. [International Classification of Diseases, 9th Revision Clinical Modification]. 8th ed. Madrid: Ministerio de Sanidad, Política Social e Igualdad, Secretaría General Técnica; 2012. Available from http://www.msc.es/ estadEstudios/estadisticas/docs/CIE9MC_8ed.pdf

20. Schmid DS, Jumaan AO. Impact of varicella vaccine on Varicella-Zoster Virus dynamics. Clin Microbiol Rev. 2010;23(1):202-17.

http://dx.doi.org/10.1128/CMR.00031-09

PMid:20065330 PMCid:PMC 2806663

21. National Statistics Institute (NSI). Population figures by Municipalities, Islands, Provinces and Autonomous Communities Madrid: NSI. [Accessed 18 Dec 2012]. Available from: http://www.ine.es/jaxi/menu.do?type=pcaxis\&path $=\% 2$ Ft20\%2Fe260\&file=inebase \& $L=1$

22. Farrington CP. Estimation of Vaccine Effectiveness using the screening method. Int J Epidemiol. 1993;22(4):742-6. http://dx.doi.org/10.1093/ije/22.4.742 PMid:8225751

23. Mullooly JP, Maher JE, Drew L, Schuler R, Hu W. Evaluation of the impact of an HMO's varicella vaccination program on incidence of varicella. Vaccine. 2004;22(11-12):1480-5 http://dx.doi.org/10.1016/j.vaccine.2003.10.021 PMid:15063572

24. Kupek E, Tritany EF. Impact of vaccination against varicella on the reduction of the disease incidence in children and adolescents from Florianopolis, Brazil. J Pediatr (Rio J). 2009;85(4):365-8. http://dx.doi.org/10.1590/So021-75572009000400016

25. Shapiro ED, Vazquez M, Esposito D, Holabird N, Steinberg SP, Dziura J, et al. Effectiveness of 2 doses of varicella vaccine in children. J Infect Dis. 2011;203(3):312-5 http://dx.doi.org/10.1093/infdis/jiq052 PMid:21208922 PMCid:PMC3071110

26. Zhou F, Harpaz R, Jumaan AO, Winston CA, Shefer A. Impact of varicella vaccination on health care utilization. JAMA. 2005;294(7):797-802.

http://dx.doi.org/10.1001/jama.294.7.797

PMid:16106004

27. Davis MM, Patel MS, Gebremariam A. Decline in varicellarelated hospitalizations and expenditures for children and adults after introduction of varicella vaccine in the United States. Pediatrics. 2004;114(3):786-92. http://dx.doi.org/10.1542/peds.2004-0012 PMid:15342855

28. Kwong JC, Tanuseputro P, Zagorski B, Moineddin R, Chan KJ. Impact of varicella vaccination on health care outcomes in Ontario, Canada: Effect of a publicly funded program? Vaccine. 2008;26(47):6006-12.

http://dx.doi.org/10.1016/j.vaccine.2008.08.016 PMid:18761386

29. Banovic T, Yanilla M, Simmons R, Robertson I, Schroder WA Raffelt NC, et al. Disseminated varicella infection caused by varicella vaccine strain in a child with low invariant natural killer T cells and diminished CD1d expression. J Infect Dis. 2011;204(12):1893-901.

http://dx.doi.org/10.1093/infdis/jir66o PMid:22043019

30. Bernstein $\mathrm{HH}$, Rothstein EP, Watson BM, Reisinger KS, Blatter $\mathrm{MM}$, Wellman $\mathrm{CO}$, et al. Clinical survey of natural varicella compared with breakthrough varicella after immunization with live attenuated $0 \mathrm{ka} /$ Merck varicella vaccine. Pediatrics. 1993;92(6):833-7. PMid:8233746

31. Brisson M, Edmunds WJ, Gay NJ, Law B, De Serres G. Analysis of varicella vaccine breakthrough rates: implications for the effectiveness of immunisation programmes. Vaccine. 2000;18(25):2775-8. http://dx.doi.org/10.1016/S0264-410X(oo)00100-6

32. Gao Z, Gidding HF, Wood JG, Maclntyre CR. Modelling the impact of one-dose vs. two-dose vaccination regimens on the epidemiology of varicella zoster virus in Australia. Epidemiol Infect. 2010;138(4):457-68. http://dx.doi.org/10.1017/So950268809990860 PMid:19781116
33. Nguyen MD, Perella D, Watson B, Marin M, Renwick M, Spain CV. Incremental effectiveness of second dose varicella vaccination for outbreak control at an elementary school in Philadelphia, Pennsylvania, 2006. Pediatr Infect Dis J. 2010;29(8):685-9.

http://dx.doi.org/10.1097/INF.obo13e3181dgf657

PMid:20354463

34. Brisson M, Melkonyan G, Drolet M, De Serres G, Thibeault R, De Wals P. Modeling the impact of one- and two-dose varicella vaccination on the epidemiology of varicella and zoster. Vaccine. 2010;28(19):3385-97. http://dx.doi.org/10.1016/j.vaccine.2010.02.079 PMid:20199763

35. Kuter B, Matthews H, Shinefield H, Black S, Dennehy P, Watson $B$, et al. Ten year follow-up of healthy children who received one or two injections of varicella vaccine. Pediatr Infect Dis J. 2004;23(2):132-7. http://dx.doi.org/10.1097/01.inf.0000109287.97518.67 PMid:14872179

36. Hope-Simpson RE. The Nature of Herpes Zoster: a Long-term study and a new hypothesis. Proc R Soc Med. 1965;58:9-20. PMid:14267505 PMCid:PMC1898279

37. Brisson M, Gay NJ, Edmunds WJ, Andrews NJ. Exposure to varicella boosts immunity to herpes-zoster: implications for mass vaccination against chickenpox. Vaccine. 2002;20(1920):2500-7. http://dx.doi.org/10.1016/S0264-410X(02)00180-9

38. Thomas SL, Wheeler JG, Hall AJ. Contacts with varicella or with children and protection against herpes zoster in adults: a casecontrol study. Lancet. 2002;360(9334):678-82. http://dx.doi.org/10.1016/S0140-6736(02)09837-9

39. Brisson M, Edmunds WJ, Gay NJ. Varicella vaccination: impact of vaccine efficacy on the epidemiology of VZV. J Med Virol. 2003;70 Suppl 1(1):S31-7.

40. Tanuseputro P, Zagorski B, Chan KJ, Kwong JC. Populationbased incidence of herpes zoster after introduction of a publicly funded varicella vaccination program. Vaccine. 2011;29(47):8580-4.

http://dx.doi.org/10.1016/j.vaccine.2011.09.024 PMid:21939721

41. Gaillat J, Gajdos V, Launay O, Malvy D, Demoures B, Lewden $\mathrm{L}$, et al. Does monastic life predispose to the risk of Saint Anthony's fire (herpes zoster)? Clin Infect Dis. 2011;53(5):405 http://dx.doi.org/10.1093/cid/cir436 PMid:21844022

42. Plotkin SA, Starr SE, Connor K, Morton D. Zoster in normal children after varicella vaccine. J Infect Dis. 1989;159(5):1000http://dx.doi.org/10.1093/infdis/159.5.1000 PMid:2540244 